\title{
Monarquías en América
}

\author{
Manuel Teruel Gregorio de Tejada \\ Dr. en Historia por la Universidad de Barcelona
}

Monarchies in America

RESUMEN

El tema del monarquismo americano no dispone de una obra seria de conjunto.

Este artículo trata de ofrecer un ensayo de síntesis global, estructurado en cuatro apartados. El primero se ocupa de los proyectos generales emanados desde la propia Monarquía hispánica: la Memoria del conde de Aranda, con la que se relacionan el informe de Campomanes, del conde de Floridablanca y la representación de José de Ábalos, durante el reinado de Carlos III, así como el proyecto de Manuel de Godoy durante el de Carlos IV. El segundo apartado describe en primer lugar las iniciativas, proyectos o intentos de establecer regímenes monárquicos dentro y después del proceso emancipador, en los que estuvieron implicados Argentina, Colombia, Ecuador, Perú y Bolivia, y a continuación las experiencias del Brasil, México y Haití, donde llegaron a crearse tales regímenes, aunque tuvieron una vida corta y agitada, con la excepción del brasileño, que subsistió durante medio siglo y con relativo sosiego. El tercer apartado esboza las iniciativas de carácter insólito o aventurero, entre los que destacan los casos de Araucania y Redonda. En el último se ofrecen las

\begin{abstract}
No reliable all-embracing work has dealt with American monarchism. This article tries to offer a syntesis in four parts. The first deals with the general projets originated in the Spanish Monarchy itself: Count of Aranda's Memoria, which is related to Counts of Campomanes' and Floridablanca's Informe and José de Abalos' Representación, all of them under the reign of Charles III, and the project of Manuel de Godoy under Charles IV's. The second part depicts the initiatives, projects and attempts to establish monarchic systems during and after the independence process, in which Argentine, Colombia, Ecuador, Peru and Bolivia were involved, and the experiences developed in Brazil, Mexico and Haiti, where such systems were held, although they had a short and uneasy life, excepted for Brazil, whose system survived rather calmly for half a century. The third part outlines some odd or hazardous initiatives, among them the cases of Araucania and Redonda. The last offers the conclusions and a general diagram.
\end{abstract}

KEYWORDS:

Monarchy / Latin America / independence 
conclusiones y un cuadro sinóptico

general.

PALABRAS CLAVE:

Monarquía / Iberoamérica / independencia

\section{PROYECTOS GENERALES EMANADOS DESDE LA PROPIA MONARQUÍA HISPÁNICA}

Es un hecho indudable que el nacimiento de los Estados Unidos de América como pueblo soberano influyó en el ánimo de las clases dirigentes españolas del Nuevo Continente, creando un precedente insoslayado para gobernantes y súbditos. Pero si este hecho está generalmente consignado por los historiadores no siempre hay coincidencias con relación a su valor causativo y hay ocasiones en que este valor llega a ser impugnado. Ya el ministro William Pitt había proyectado en 1762 que un príncipe real de Gran Bretaña tomara las riendas del gobierno de las trece colonias americanas. Este príncipe podría ser alguno de los cuatro hermanos del rey George III: Edward, duque de York, William, duque de Gloucester, Henry Frederick, duque de Cumberland, o Frederick William.

Y asimismo produjo una fuerte impresión en el ánimo de los estadistas españoles de fines del siglo XVIII, de una manera singular en Pedro Abarca de Bolea, conde de Aranda, y en José Moñino, conde de Floridablanca. Fruto de una impresión de tal índole es la Memoria secreta presentada a Carlos III después de firmado el tratado de París de $1783^{1}$, cuya paternidad, atribuida al primero, ha suscitado controversias. En ella aparece claro un remedio para salir al paso del movimiento emancipador hispanoamericano, fríamente intuido, por lo demás, por el propio conde de Aranda. Me refiero a la división de la mayor parte de los territorios de la América española en varias monarquías que se mantendrían independientes, aunque unidas por ciertos vínculos a la Metrópoli o, al menos, con una dependencia sobre la base de dotar de amplia autonomía a la existente organización virreinal. En ambos casos los nuevos reyes o virreyes habrían de ser príncipes de la sangre, concretamente infantes de España, y el rey de las Españas y de las Indias asumiría el título de emperador, como se afirma en el texto:

«Que V.M. se desprenda de todas las posesiones del Continente de América, quedándose únicamente con las Islas de Cuba y Puerto Rico en la parte septentrional y algunas que más convengan en al meridional, con el fin de que ellas sirvan de escala o depósito para el comercio español.

1 Rojas Mery, E.: Independencia de Sudamérica hispana. Su grandeza y miserias, Montevideo, 1946, p.14, cita el año 1786. El texto de la Memoria (o dictamen reservado) puede verse en LuCENA GIRALDO, M.: Premoniciones de la Independencia de Iberoamérica, Madrid, 2003, pp. 74-85. 
Para verificar este vasto pensamiento de un modo consecuente con la España se deben colocar tres infantes en América, el uno de rey de México, el otro del Perú y el otro de los restantes de la Tierra Firme, tomando V.M. el título de Emperador».

Por estas fechas sólo vivían, excluido obviamente el príncipe de Asturias (el futuro Carlos IV), tres infantes: Luis, conde de Chinchón (1727-1785), hijo menor de Felipe V, Gabriel (1752-1788) y Antonio (1755-1817), ambos hijos de Carlos III. Solamente ellos, pues, hubieran podido ocupar los proyectados tronos ultramarinos, aunque los infantes Luis y Gabriel fallecerían poco después², mientras un hijo del segundo, el infante Pedro (1786-1812), podría haber sido un nuevo candidato. Ahora bien, no es en la Memoria citada donde figura por primera vez este proyecto preventivo, resucitado en más de una ocasión en años posteriores y que me ha servido de punto de partida porque es el más conocido.

Por lo que se refiere a otros territorios americanos no españoles, Enrique de Gandía cita como precursor el aludido proyecto de 1762, del ministro Pitt, con respecto a las colonias británicas ${ }^{3}$, donde en tiempos de la guerra de independencia norteamericana algunos congresistas escribieron, al parecer, una carta al príncipe Charles Edward (el Bonnie Prince Charlie), autodenominado duque de Albany (1720-1788), nieto de del rey James II, ofreciéndole una hipotética corona.

Relacionado sin duda con la Memoria, por lo menos en cuanto al objetivo que ésta perseguía, se encuentra un dictamen de los fiscales del Consejo de Castilla Pedro Rodríguez Campomanes y José Moñino, luego condes de Campomanes y de Floridablanca, respectivamente, citado por Richard Konetzke y expuesto en la sesión extraordinaria de 5 de marzo de 1768, presidida por el conde de Aranda. Este dictamen propone como medios para prevenir la independencia, entre otros, valerse de la atracción de los americanos por los estudios en la $\mathrm{Pe}$ nínsula; concederles un número determinado de plazas en la tropa; enviar españoles de la Metrópoli a Ultramar para que desempeñasen cargos principales y, a su vez, españoles ultramarinos a aquélla para ejercer los equivalentes; y nombrar un diputado en la Corte como representante de cada uno de los distritos de los tres virreinatos y de Filipinas ${ }^{4}$.

Con posterioridad a este dictamen José de Ábalos, intendente de Ejército y Real Hacienda de la gobernación y capitanía general de Venezuela, envió a Car-

${ }^{2}$ El 11 de junio de 1783 había muerto el infante Carlos, hijo del príncipe de Asturias, con tres años de edad, y aunque el 5 de septiembre del mismo año nacieron dos mellizos, otro Carlos y Felipe, también fallecieron sin alcanzar los dos años.

${ }^{3}$ GANDíA, E. de: Conspiraciones y revoluciones de la independencia americana. Movimientos precursores, Buenos Aires, 1960, p. 13.

${ }^{4}$ KONETZKE, R.: «La condición legal de los criollos y las causas de la infidencia» Estudios Americanos, 2 n. ${ }^{\circ}$ 5, pp. 31-57 (la referencia en pp. 45-46). Del dictamen se hacen eco también LEVENE, R.: El mundo de las ideas y la revolución hispanoamericana de 1810, Santiago de Chile, 1956, p. 43, y DELGADO, J.: La independencia hispanoamericana, Madrid, 1960, pp. 22-24. 
los III una representación, fechada el 24 de septiembre de 1781, de la que ha dado amplia noticia Carlos E. Muñoz Oraá, quien inserta asimismo el texto de la Memoria ${ }^{5}$. En resumen se pedía al rey que

«[...] el heroico pecho de V.M. se digne resolverse con su regia generosidad a desprenderse de las provincias comprendidas en los distritos a que se extienden las audiencias de Lima, Quito, Chile y La Plata, como asimismo de las Islas Filipinas y sus adyacencias, exigiendo y creando de sus extendidos países tres o cuatro diferentes monarquías a que se destinen sus respectivos príncipes de la augusta Casa de V.M.»

Los candidatos a los tronos de las monarquías proyectadas en esta representación no podían ser otros que los ya mencionados Luis, Gabriel y Antonio.

El proyecto de Ábalos coincide fundamentalmente con el expresado en la $\mathrm{Me}$ moria, pero aparecen claras ciertas diferencias: el primero incluye Filipinas y no menciona Nueva España; el segundo, por el contrario, calla sobre Filipinas y propugna un reino de México. Ábalos no delimita las eventuales monarquías, sino únicamente señala el número de tres o cuatro; la Memoria, en cambio, habla de los reinos de México, El Perú y el resto del territorio continental. El intendente venezolano no aconseja reservarse otros territorios, mientras que el pretendido proyecto arandino insinúa conservar Cuba, Puerto Rico y algunas posesiones de América del Sur. Más adelante un historiador contemporáneo de los procesos emancipadores, José de Presas ${ }^{6}$, insistirá en esta última consideración y es interesante observar que estas provincias fueron las últimas que lograron la independencia de la Metrópoli. Por fin, la Memoria se extiende además en detallar las funciones políticas de las futuras monarquías.

La paternidad de esta Memoria ha sido negada en varias ocasiones al conde de Aranda, tomándose como base principal la ausencia del documento original, como apunta Manuel Ballesteros, del que solamente existen copias ${ }^{7}$. Así Andrés Muriel, su primer divulgador, cita un manuscrito perteneciente a la colección de Joaquín José de Melgarejo, duque de San Fernando de Quiroga, yerno del citado infante Luis, conde de Chinchón, lo mismo que Modesto Lafuente ${ }^{8}$, quien añade que

5 Muñoz OraÁ, C.E.: «Pronóstico de la independencia de América y un proyecto de monarquías en 1781», Revista de Historia de América, 50 (Mex. 1960), pp. 439-473, pp. 460-461. El texto de la representación puede verse en LuCENA GIRALDO, M.: Premoniciones..., pp. 54-73.

6 PRESAS, J. de: Juicio imparcial sobre las principales causas de la Revolución de la América española y acerca de las poderosas razones que tiene la Metrópoli para reconocer su absoluta independencia, Burdeos, 1828, pp. V y 120.

7 Ballesteros Gaibrois, M.: Historia de América, Madrid, 1962, pp. 487-488. Las copias pueden verse en Coxe, G.: España bajo el reinado de la casa de Borbón, IV, parte adicional al cap. $3 .^{\circ}$, escrita por A. Muriel, pp. 432-439; Odriozola, M. de: Documentos literarios del Perú, VIII, Lima, 1875, pp. 535-539; Muñoz OraÁ, C.E.: «Pronóstico....», pp. 470-473; y MoRA, J.M.L.: México y sus revoluciones, II, México, 1950, pp. 242-248 (en nota).

8 COXE, G.: España..., p. 432; LAfUente, M.: Historia general de España, XXI, Madrid, 1858, p. 169 (en nota). 
hay noticias en el Archivo General de Simancas de haberse entregado al duque copias de muchos papeles pertenecientes a la correspondencia de embajadores españoles del siglo XVIII —Aranda lo había sido en París-, haciendo notar que uno de sus archiveros, apellidado González, era amigo particular del citado duque. Boleslao Lewin, por su parte, afirma que fue este último quien entregó el documento a Muriel, que era ministro de Estado.

Por otro lado, el texto utilizado por Muñoz Oráa se conserva en el Archivo General de Indias ${ }^{9}$, enviado por Rafael Morant en 1825 -la carta que lo acompaña está fechada en Madrid el 9 de diciembre- a Pedro de A. Álvarez de Toledo, duque del Infantado, quien sin duda lo remitió al Archivo. Es el mismo, también, al que se refiere Pedro Torres Lanzas; en cambio Benito Sánchez Alonso cita un manuscrito existente en la Biblioteca de Ultramar, que hoy engrosa los fondos de la $\mathrm{Bi}$ blioteca Nacional de Madrid. Y Manuel Danvila hace alusión a un texto que se haIla, dice, en la biblioteca de Antonio Cánovas del Castillo ${ }^{10}$.

No reconocen al conde de Aranda como el autor de la Memoria, junto con Whitaker, que la atribuye a Godoy, Ferrer del Río, Baumgarten, Konetzke y Gandía, más radical éste en sus conclusiones. Afirman o, al menos no niegan su paternidad, Muriel, Lafuente, Danvila, Navarro Lamarca, Mora, Teja, García Samudio, Sarrailh, Lewin, Encina, Labra, Levene, Sagnac y Vadillo, entre otros. No me detengo en las razones aducidas en la controversia - abundan argumentos de matiz psicológico e indirectos-, pues lo que interesa aquí es el contenido del proyecto, reflejo de la conciencia política del momento y su repercusión posterior. Muriel hace una crítica favorable a la Memoria, lamentándose de las miras poco generosas del gabinete de Carlos III, por una parte, y calificándola, por otra, de patriótica y adecuada para llegar con moderación y sin sacudimientos a una emancipación que juzga útil para España y puesta en armonía con las opiniones e intereses de las provincias ultramarinas. Intereses que intenta probar trayendo a colación el hecho, contemporáneo para él, de los planes de Agustín Iturbide de colocar un infante de España en el trono del viejo imperio azteca, del que hablaré luego ${ }^{11}$.

La opinión de los historiadores sobre el proyecto esbozado en la Memoria es diversa. Francisco A. Encina le atribuye la eficacia de acortar la duración del dominio español en América; califica como visión clarividente de la realidad la exposición general del mismo, aunque la proyectada división de monarquías la tiene por fantasía exaltada y quimera, e integra en lo que sería el reino de México la capitanía general de Guatemala; en el de Tierra Firme el virreinato de Nueva Granada y la capitanía general de Venezuela; y en el del Perú el virreinato del Río de La Plata y la capitanía general de Chile. Finalmente, no ve en el plan un remedio para

9 Archivo General de Indias, Estado, leg. 91.

10 Torres Lanza, P.: Independencia de América. Fuentes para su estudio. Colección de documentos conservados en el Archivo General de Indias de Sevilla, segunda serie, I, Sevilla, 1924, p. 31, nota 108. Cita la signatura antigua, Estado, América general, leg. 6, n. 2, y pone el año 1783 en interrogación.

11 COXE, G.: España..., pp. 439-440. 
la total emancipación, sino únicamente una nueva modalidad del proceso revolucionario que casi seguramente, dice, habría tomado el camino del seguido por El Brasil $^{12}$.

Nicolás García Samudio ${ }^{13}$ reconoce la visión política del autor de la Memoria, pero en cuanto se refiere a la conciencia de una cercana escisión, reconocimiento muy generalizado y expresado muchos años antes por un historiador contemporáneo de la emancipación, José Manuel de Vadillo, consejero honorario de Estado, al enjuiciar los principales acontecimientos relacionados con la emancipación ${ }^{14}$. En este sentido Manuel M. Moreno ${ }^{15}$ da un paso adelante cuando ve en el conde de Aranda a un simpatizante de la idea de independencia, lo que es cierto en el sentido restringido que la Memoria permite. Mas para él esta simpatía nacería del hecho de que la emancipación de los pueblos americanos formaba parte, dice, del plan de acción puesto en marcha por las sociedades secretas del Nuevo y del Viejo Mundo.

El valor profético, o previsor, del documento está ampliamente destacado por Boleslao Lewin quien, con argumentos intrínsecos y de matiz psicológico, trata de probar la paternidad arandina de la Memoria exponiendo el pensamiento del conde a través de sus escritos. Esta previsión está puesta de relieve también por Sagnac, Mora y Sarrailh, quien cita la propia frase de Aranda cuando escribía a Floridablanca: Me he Ilenado la cabeza de que la América meridional se nos irá de las manos. ¿Sería esta conciencia de los políticos ilustrados un motivo más del escaso interés de los liberales de la primera experiencia constitucional ante un hecho que se estaba consumando? ${ }^{16}$.

12 Encina, F. A.: Bolívar y la independencia de la América española. El imperio hispano hacia 1810 y la génesis de su emancipación, Santiago de Chile, 1957, p. 346. En nota observa que el plan es esencialmente el del misionero jesuita Pedro Calatayud. Desconozco a qué plan se refiere, pero no alcanzo a comprender cómo este jesuita, que murió en 1773 y se dedicó plenamente a las misiones populares por toda la Península, se implicó, o lo implicaron, en un asunto de alta política ultramarina. ¿Acaso Encina se refiere al mercedario limeño Cipriano Calatayud (1735-1814)?

13 García SAmudio, N.: La independencia de Hispanoamérica, México, 1945, p. 16.

14 Vadillo, J.M. de: Apuntes sobre los principales sucesos que han influido en el actual estado de la América del Sur, Cádiz, 1836 (3. ${ }^{a}$ ed.), pp.239-240. La primera edición (Londres, 1829) y la segunda (París, 1830) no hablan del proyecto de Godoy, del que me ocupo más arriba, pues éste no había publicado aún sus Memorias. Reconocen la visión política de la Memoria Fernández Almagro, M.: La emancipación de América y su reflejo en la conciencia española, Madrid, 1967 (2. ${ }^{a}$ ed.), p. 19; ENCINA, F. A.: Bolívar..., p. 348; LABRA, R. M. de: La pérdida de las Américas (Recuerdos históricos), Madrid, 1869, p. 43 (en nota); LeVENE, R.: El mundo..., p. 101; LEWIN, B.: Los movimientos de emancipación en Hispanoamérica y la independencia de Estados Unidos, Buenos Aires, 1952, pp.44-51; MorA, J.M.L.: México..., pp. 242-248; SAGNAC, P.: La fin de l'Ancien Régime et la revolucion américaine (1763-1789), París, 1952, p. 398; y SARRAILH, J.: La España ilustrada de la segunda mitad del siglo XVIII, México/Buenos Aires, 1957, pp. 587-588, aunque para éste predomina la opinión del conde de Fernán Núñez (Vida de Carlos III, pp. 286-298) de que el estado de las poblaciones hispanoamericanas eliminó por mucho tiempo el peligro.

15 Moreno, M. M.: Génesis sociológica de la independencia hispanoamericana, México, 1952, p. 17.

16 LeWIN, B.: Los movimientos..., pp. 43-53; SAGnAC, P.: La fin...p. 398; MorA, J.M.L.:, México..., p. 242; y SARRAILH, J.: La España..., p. 587. 
Encina y Fernández Almagro, en fin, nos hablan de una nueva variante del plan, totalmente revolucionaria, aparecida en 1787 e insinuada por el propio conde de Aranda al conde de Floridablanca con estas palabras:

«Yo soñaría en adquirir el Portugal con el Perú, que por sus espaldas se uniese con el Brasil [...] Establecería un infante en Buenos Aires, dándole también el Chile; si sólo dependiese del agregar éste al Perú para hacer inclinar la balanza a gusto del Portugal a favor de la idea se lo diera igualmente reduciendo el infante a Buenos Aires y dependencias ${ }^{17}$ »

El infante tendría que ser alguno de los mencionados más arriba, salvo Luis quien ya había fallecido. No cabe duda de que estos planes eran producto de la fantasía, como lo confirman las propias palabras empleadas por Aranda en la sugerencia: Yo soñaría...

A principios del siglo XIX se consideró bajo reserva un nuevo proyecto, vinculado estrechamente al anterior y revelado en 1829, como afirma José Manuel de Vadillo $^{18}$, y cuyo autor fue Manuel de Godoy, príncipe de la Paz. Pero así como durante el reinado de Carlos III no se llevaron a la práctica los planes entonces esbozados, su sucesor Carlos IV tampoco facilitó la realización de este nuevo plan. A juzgar por el mismo príncipe de la $\mathrm{Paz}^{19}$, la acogida por el rey fue favorable, pero llegando a dudar de si alcanzaban sus facultades para tanto. Y, rota la paz con Gran Bretaña, temió exponer a sus hijos Carlos (1788-1855) y Francisco de Paula (1794-1865), a su hermano Antonio y a su sobrino Pedro, estos dos últimos ya citados, a los peligros de un viaje ultramarino. Carlos IV decidió, pues, consultar a José Antonio Caballero, ministro de Gracia y Justicia, y a pesar de que su respuesta fue negativa determinó que se pidiera el parecer de los más acreditados obispos del reino. Los ocho elegidos, según Godoy, aprobaron el plan, así como varios consejeros más, con los que el rey había hablado reservadamente. José Manuel de Vadillo, al que siguen Encina y Gandía ${ }^{20}$, basándose en el parecer de los prelados, resalta la ocasión que se le presentaba a Godoy de conseguir la soberanía de eventuales monarquías; incluso supone ser éste el exclusivo objetivo del intento, insinuando además que el impedimento para que el plan se llevase a efecto fue la perspectiva que pronto se le ofreció de obtener una soberanía europea, más halagüeña.

17 Encina, F.A.: Bolívar..., p. 348; y Fernández Almagro, M.: La emancipación...p. 19.

18 Cf. Gandía, E. de: Conspiraciones..., p. 14.

19 Godoy Álvarez de FARIA, M. de: Memorias críticas y apologéticas para la historia del reinado del Señor Don Carlos IV de Borbón (edición y estudio preliminar de Carlos Seco Serrano), Madrid, 1956, I, p. 419. Corona Baratech, C.: «Presentimiento de la emancipación hispanoamericana», Estudios Americanos, 2, n. ${ }^{\circ} 6$ (1950), pp. 237-242, en p. 242 afirma que el concepto patrimonial de la Monarquía, en Carlos IV, está ausente en la tradición española.

${ }_{20}$ Vadillo, J.M. de: Apuntes..., p. 249; Encina, F.A.: Bolívar..., p. 348; y Gandía, E. de: Conspiraciones..., p. 14. La cesión de un reino a Godoy estaba en el ánimo de Carlos IV, como se verá más adelante. 
El pensamiento del príncipe de la Paz respecto a este plan de división monárquica de las provincias españolas de América se centraba más en la estructura jurídico-política de los eventuales reinos que en la demarcación territorial de los mismos. Insistía en que fuesen infantes de España los elegidos para ponerse al frente de cada uno de ellos, pero sólo con el título de príncipes regentes o virreyes perpetuos y hereditarios, no de rey, que se hiciesen amar allí y que llenasen con su presencia la ambición y el orgullo de aquellos naturales. El prever mejor una práctica sustitución de los virreyes ya existentes por estos príncipes regentes parece indicar que deberían conservarse los límites territoriales vigentes, aunque tal vez con alguna variante. Tales príncipes deberían ser ayudados en la función de gobierno por un Consejo de ministros responsables y respaldados en la tarea legislativa por un cuerpo colegial, un Senado, integrado por miembros nativos y de la Metrópoli en idéntica proporción numérica. En cuanto a la legislación insinuaba una acomodación de las Leyes de Indias a los tiempos que corrían; y con respecto al poder judicial reclamaba tribunales propios, en última instancia, para cada uno de los principados regencias, salvo el caso en que un interés común a América y a la Metrópoli requiriese una vista en ésta.

El plan parecía estar diseñando un boceto de una hipotética monarquía constitucional, pero faltaban elementos esenciales: la nación, o el pueblo, como sujeto de la soberanía y la carta fundamental que consagra este principio, pues el verdadero soberano seguía siendo el rey de las Españas y de las Indias. Más aún, el propio Carlos IV, en la referida consulta a los obispos hablaba, en términos anacrónicos, del establecimiento en América de una Soberanía Feudal de la España. Godoy llegaba a dar una trascendencia desorbitada a su proyecto, pues de haberse realizado, afirma, Napoleón no hubiese invadido la Península ni llevado a cabo el traslado de la familia real española a Francia, además de que se habrían conservado los vínculos con las posesiones ultramarinas.

Para algunos, como Whitaker y Gandía ${ }^{21}$, este proyecto de Godoy y la Memoria arandina son una misma cosa. Cierto o no, la idea fundamental, salvo modificaciones de época, es la misma. El propio ministro de Carlos IV prevé la objeción y no la desmiente al afirmar:

«Dirá tal vez alguno que este proyecto no fue nuevo y que el conde de Aranda lo había propuesto ya veinte años antes [...] Nada por cierto tendré que avergonzarme de haber reproducido un pensamiento ajeno que hubiese sido favorable a la Corona y a mi patria».

Pero, a pesar de todo, él mismo ve una motivación diferente: juzga que la Memoria, que proponía una enajenación de todo el Continente, era un proyecto enteramente francés, mientras que el suyo era completamente español, al tiempo que

21 Whitaker, A.P.: «The Pseudo-Aranda memoir of 1783», Hispanic Historical Review, 17 (1937), pp. 287-313; y GandíA, E. de: Conspiraciones..., p. 14. 
atribuye la desgracia de Aranda durante el último período del reinado de Carlos III a las propuestas contenidas en aquélla ${ }^{22}$. Es difícil calibrar el grado de patriotismo intencional de los autores de ambos textos, no excluidas posibles ambiciones personales, cuando trataban de dar una solución adecuada a un futuro problema secesionista en Hispanoamérica. Pero no hay que olvidar que el príncipe de la Paz había tenido mejor ocasión de inspirarse, y de hecho se inspira, en las consecuencias políticas de las doctrinas de la Revolución; $y$, por otra parte, el sentimiento de patria estaba más perfilado en los años en que él escribe sus Memorias y aún mejor después de su caída.

La mencionada consulta que Caballero transmitió a los obispos, acompañada de un oficio reservado, por orden y de puño y letra de Carlos IV, se expresa en los siguientes términos:

«Habiendo visto por la experiencia que las Américas estarán sumamente expuestas y aún en algunos puntos imposibles de defender por ser una inmensidad de costa, he reflexionado que sería muy político, y casi seguro establecer en diferentes puntos de ella a mis dos hijos menores, a mi hermano, a mi sobrino el Infante don Pedro y al Príncipe de la Paz, en una Soberanía Feudal de la España, con títulos de Virreyes perpetuos, y hereditaria en su línea directa, y en caso de faltar ésta reversiva a la Corona, con ciertas obligaciones de pagar un tributo que se les imponga, y de acudir con tropas y navíos donde se les diga, me parece que además de político, voy a hacer un gran bien a aquellos naturales, así en lo económico como principalmente en la Religión, pero siendo una cosa que tanto puede gravar mi conciencia, no he querido tomar resolución sin oír antes Vuestro dictamen, estando muy cerciorado de vuestro talento, cristiandad, celo de las almas que gobernáis, y del amor a mi servicio, y así espero que a la mayor brevedad respondáis a esta carta, que con la importancia del secreto va toda de mi puño, así lo espero del acreditado amor que tenéis al servicio de Dios, y a mi persona, y os ruego me encomendéis a Dios para que me ilumine y me dé su Santa Gloria. San Lorenzo y octubre 7 de 1806. Yo el Rey ${ }^{23}$ ».

Uno de los prelados consultados, el ilustrado Félix Amat de Palou, arzobispo titular de Palmira y abad de San Ildefonso de La Granja, previendo la dificultad de conservar las provincias ultramarinas, al menos de forma que compensasen los esfuerzos y gastos de tal conservación, aprobó la idea, como asegura Encina ${ }^{24}$. Pero otro, Romualdo Mon y Velarde, arzobispo de Tarragona, expuso los temores de que los súbditos americanos, particularmente sus descendientes, olvidándose del beneficio de la autonomía, romperían su vinculación con el rey y se apresuraría la independencia, según expone Vadillo25.

22 Godoy Álvarez de Faria, M. de: Memorias ..., I, pp. 419-420.

23 El texto es el que ofrece EncinA, F.A.: Bolívar..., p. 349 y que fue dirigido al arzobispo Félix Amat de Palou. GandíA, E. de: Conspiraciones..., p. 14; y VAdillo, E. de: Apuntes..., p. 248, ofrecen también el que fue enviado al arzobispo Romualdo Mon. Ambos textos, y probablemente los remitidos a los seis obispos restantes, coinciden esencialmente, pero tienen algunas pequeñas variantes; ignoro si éstas se deben a la redacción original o a copias posteriores.

24 Encina, F.A.: Bolívar..., p. 349.

25 Vadillo, J.M. de: Apuntes..., p. 249. 
Los autógrafos, tanto de la carta de Carlos IV como del oficio de Caballero y de la minuta de la respuesta del arzobispo Mon, los vio el mismo Vadillo; se conoce, pues, el texto de la carta, aunque sus divulgadores no citan el origen; del oficio y de la respuesta queda indicada la opinión escueta, pero desconozco el texto, que sin duda se conserva. No obstante, puedo hablar de una pista que hallé en Sevilla, expresión, por lo demás, de un raro interés por las cosas de América en un momento en que la Península se debatía entre enconadas luchas ideológicas, en un prolongado afán de constituirse. Se trata de un manuscrito autógrafo de Francisco Martínez de la Rosa, fechado en París el 20 de noviembre de 1842, con un encargo para su amigo Manuel López Cepero, deán del cabildo metropolitano de Sevilla y diputado en las Cortes de 1813 y $1820^{26}$. En él solicita información sobre los mencionados documentos, de los que da la siguiente noticia: cuando murió en 1819 el arzobispo Mon, quien desde 1816 ya lo era de Sevilla, su albacea testamentario, Fuentes, doctoral del cabildo de la Capilla Real de la catedral y luego diputado en las Cortes de 1820-1823, encontró entre sus papeles tales documentos - la carta fue reconocida años después por el que fue ministro de Estado (18001809), Pedro Ceballos, como autógrafa de Carlos IV- que quedaron en poder de sus hermana y sobrina, vecinas de una casa de la calle de la Pajería, a la muerte del doctoral. El que suministra estos datos testimonió a Martínez de la Rosa haberlos visto en posesión de aquéllas; finalmente, la información pedida debía dirigirse directamente a Ángel Saavedra, duque de Rivas, en Sevilla, o a José Ruiz de Arana, cuñado de éste, en Madrid.

\section{PROYECTOS Y REALIZACIONES DENTRO Y DESPUÉS DEL PROCESO EMANCIPADOR}

Hasta aquí he tratado de esbozar los proyectos generales que, de alguna forma, pretendían frenar o, al menos encauzar, el naciente proceso emancipador en las provincias ultramarinas, sin que se pudiera lograr. Ahora conviene tener conocimiento de las bases ideológicas y culturales de la emancipación hispanoamericana en relación con una adecuada y legítima organización política. En el cúmulo de ideas circulantes, y como resultado del enfrentamiento entre la mentalidad coIonial metropolitana y la criolla, Mario Hernández ${ }^{27}$ ofrece dos variantes fundamentales: la peninsularista, promovida por los virreyes y altos funcionarios de la Corona, de corte continuista, y la criollista, muy diversificada. Pues bien, dentro de esta última cabe incluir las de monarquía sin rey, con predominio social aristocrático, y la de la monarquía transaccional y pactada con algunas dinastías extranje-

26 Sobre López Cepero, personaje notable en la política de la primera mitad del siglo XIX, pueden verse mis artículos «Rasgos claves de la vida de Manuel López Cepero», Archivo Hispalense, n. ${ }^{\circ} 124-$ 125 (1964), pp. 157-191; «Ideología política del diputado de Cádiz Manuel López Cepero», Ibidem, n. ${ }^{\circ}$ 139-140 (1966), pp. 217-246; y «Un desacuerdo amigable sobre afrancesados entre Reinoso y López Cepero», Caleta, n. ${ }^{\circ}$ homenaje a J.M. Pemán (ag. 1967), s.p.

27 Hernández SÁnchez-Barba, M.: Historia de América, IV, Madrid, 1986 (2. a ed.), p. 108. 
ras, incluida la línea bonapartista de José, quien ya había ostentado la Corona española durante la guerra de la Independencia.

Paralelamente, en el proceso de afianzamiento de las nuevas nacionalidades americanas logradas jugó un papel importante la búsqueda del sistema político más conveniente para poder gobernar. En ella se enfrentaron conservadores y liberales nativos, entre los que cabe destacar a Lucas Alamán en el primer grupo y a Juan B. Alberdi y Faustino Sarmiento en el segundo. Los conservadores esperaban que una monarquía constitucional, según el modelo de Cádiz, vigente desde 1812, podría cristalizar con relativa facilidad. Los liberales, por el contrario, pensaban que el establecimiento de una monarquía tradicional y autoritaria, aunque no absoluta, supondría la pervivencia de los viejos esquemas y valores defendidos por los hacendados (conservadores) y, por ello, se inclinaban por la forma de gobierno republicano, centralista o federalista, más cercana al sistema democrático que ofrecía el modelo norteamericano, y a la filosofía del momento (Locke, Montesquieu, Rousseau). El fracaso de la experiencia monárquica mexicana, de la que me ocupo más adelante, fortalecería los argumentos republicanistas ${ }^{28}$.

Pero al estar reflejados en Hispanoamérica los mecanismos estamentales de la Metrópoli, la vivencia de la Monarquía o sus instituciones marcó, como dice Juan Beneyto ${ }^{29}$, el debate de tal proceso. Por ello, llegada la hora de la eclosión independentista y en conexión con ella, fueron apareciendo proyectos o intentos monárquicos parciales, nacidos en el propio escenario de los conflictos, que no llegaron a madurar. Así, en el virreinato del Río de la Plata son muestras un Reglamento que reconocía a Fernado VII, pero con predominio del poder legislativo, y la exposición de Juan José Castelli en el cabildo abierto de 22 de mayo de 1810 para la creación de la primera Junta que, creada el 24, cayó días después ${ }^{30}$; y en Chile el Reglamento de 1812, que preveía una monarquía centrada en el poder ejecutivo ${ }^{31}$. Otros proyectos fueron propiciados por instancias foráneas, como el francés de 1819, citado por Caracciolo Parra Pérez ${ }^{32}$, del que se hicieron eco impresos publicados en Buenos Aires, de crear un reino en el territorio del virreinato del Río de la Plata, con sede en su capital, y cuya corona ceñiría el infante Carlos Luis (1799-1885), duque de Lucca, ex rey de Etruria (Luigi II) y más tarde duque de Parma (Carlo II), sobrino de Fernando VII (hijo de su hermana Luisa).

28 Cf. M. Hernández Sánchez-Barba, en L. NavarRo García (coord.): Historia de las Américas, IV, pp. 135-137.

29 BeneYto, J.: «La sustitución de los estamentos tradicionales en España y en Hispanoamérica», Estudios Americanos, 20 n. ${ }^{\circ} 103$ (1960), pp. 1-13, pp. 8-9.

30 Cf. Marfany, R. H.: «Filiación política de la revolución de Buenos Aires en 1810», Estudios Americanos, 21 n. 108 (1961), pp. 235-253, pp. 235-236. Ver asimismo, CoRREA LuNA, C.: Rivadavia y la simulación monárquica de 1815, Buenos Aires, 1929; LeVENE, R.: Historia de la nación argentina desde los orígenes hasta la organización definitiva en 1862, Buenos Aires, 1950, 6 vols.; y GANDíA, E. DE: Historia de las ideas políticas en la Argentina, IV, Buenos Aires, 1960.

31 Cf. Historia de las Américas..., IV, pp. 164-173; y Marfany, R.H.: «Filiación...», pp. 235-236.

32 Parra Pérez, C.: La monarquía de la Gran Colombia, Madrid, 1957, pp. XVI-XVIII. 
En el virreinato de Nueva España se había producido en 1816 un intento monárquico, aunque con escasas posibilidades de éxito: Javier Mina, sobrino de Espoz y Mina, al frente de un grupo independentista ofreció a José Bonaparte, en su residencia norteamericana de Pont Breese - usaba entonces como título de cortesía el de conde de Survilliers - una hipotética corona imperial de México. Pero las vivencias políticas en el exilio del hermano mayor de Napoleón y, tal vez, el cercano rechazo a su experiencia monárquica en la Metrópoli le movieron no sólo a declinar el ofrecimiento sino a aconsejar el régimen republicano como más apto para los nuevos Estados ultramarinos ${ }^{33}$.

Más elaborado, con base más amplia e incluso concertado por los bandos contendientes, se logró un pacto, formulado en el Plan de Iguala, suscrito y publicado en la villa del mismo nombre el 24 de febrero de 1821 y jurado el 1 marzo siguiente. El plan ofrecía tres garantías: religión, que significaba fidelidad al catolicismo (color blanco de la bandera), independencia, bajo un régimen monárquico (color verde) y unión de todos los ciudadanos sin exclusión de raza o de origen (color rojo). El plan fue aceptado por el ejército, el clero y las autoridades, salvo excepciones, y ratificado el 24 de agosto por el virrey Juan O’Donojú.

En su cláusula segunda se propugnaba el establecimiento de una monarquía moderada, con la absoluta independencia del virreinato, cuyo trono se ofrecía al propio Fernando VII o a algún infante de España y, en defecto de ellos, a uno de los archiduques de Austria nietos de Carlos III. Infantes de España sólo vivían entonces los hermanos del rey, Carlos (1788-1855) y Francisco de Paula (1794-1865), y un sobrino segundo, Sebastián (1811-1875), hijo del fallecido infante Pedro (eventual candidato en la Memoria del conde de Aranda), además del ya citado Carlos Luis, duque de Lucca. Archiduques de Austria nietos de Carlos III (hijos de su hija la emperatriz María Luisa) vivían Karl, duque de Teschen (1771-1847), Joseph, paladín de Hungría (1776-1847) y Rainer, gobernador de Lombardía (1783-1853), excluyendo obviamente al emperador Franz I, a Ferdinando III, gran duque de Toscana, y a Rudolf, cardenal y príncipe-arzobispo de Olmutz. Este ofrecimiento, calificado por José de Presas de muy ventajoso sin expresar los motivos, no tenía otro objetivo, a juicio de Domingo Amunátegui, que conquistar los ánimos de los realistas, ya que se juzgaba impracticable ${ }^{34}$. La paradoja de ofrecer la corona a quien ya era rey de las Españas y de las Indias resultaba sólo aparente, pues con independencia de la nueva estructuración monárquica, por esas mismas fechas se daba un caso similar que tuvo realidad en Brasil, como luego se verá.

El Plan de Iguala fue recogido en sus líneas generales el 25 de agosto de 1821 por el Tratado de Córdoba, firmado por el generalísimo Agustín de Iturbi-

${ }^{33}$ Cf. el estudio sobre la vida privada de José Bonaparte en América, de Georges Bertin, publicado en París en 1893; y PARRA PÉrez, C.: Bayona y la política de Napoleón en América, Caracas, 1939.

34 PRESAS, J. de: Juicio imparcial..., p. 118; AmunáteguI SolAR, D.: La emancipación hispanoamericana, s. I., 1936, p. 23; Cf. asimismo, CuE CÁnovAs, A.: Historia social y económica de México. La revolución de independencia y México hasta 1854, México, 1947; O’GumAN, E.: La supervivencia política novo-hispana. Reflexiones sobre el monarquismo mexicano, México, 1969; y HANNET, B.: Revolución y contrarrevolución en México y El Perú: liberalismo, realeza y separatismo (1800-1824), México, 1978. 
de y Arámburu y refrendado por el virrey Juan de O'Donojú, donde se estipulaba la independencia de Nueva España. El tratado, sin embargo, no logró el respaldo de las Cortes de Madrid que consideraron que el virrey se había extralimitado en sus facultades. Con relación a la referida cláusula segunda se introducían algunas modificaciones: además de a Fernando VII, se aludía expresamente como eventuales monarcas sólo a los infantes Carlos, Francisco de Paula y Carlos Luis y se excluía a los archiduques nietos de Carlos III. Al mismo tiempo se preveía que en el caso de no aceptación por el rey o por los infantes se eligiese a cualquier persona que el Congreso del Imperio designe; entretanto funcionaría una regencia, que presidiría Agustín de Iturbide, y se crearía un imperio mexicano cuyo monarca llevaría el título de emperador constitucional.

En previsión de esta cláusula y tras el abandono de O'Donojú, Iturbide entró en la ciudad de México el 27 de septiembre de 1821 y durante ocho meses desempeñó la aludida regencia, esperando que las personas a quienes se ofreció la corona aceptasen, mientras el poder legislativo, de donde procedería cualquier decisión política, lo ejerció la Soberana Junta Provisional Gubernativa, que se había establecido el 28, formada por treita y ocho miembros y presidida por el propio Iturbide. Ésta publicó el Acta de Independencia y convocó un Congreso Constituyente, que se reunió el 24 de febrero de 1822, integrado por tres partidos, el borbonista, el republicano y el iturbidista, y sancionó el 19 de mayo la proclamación de aquél como emperador, con el nombre de Agustín I, hecha por el ejército el día anterior. El nuevo monarca aceptó el 22, juró y fue coronado, con su mujer, Ana María Huarte y Muñiz, el 21 de julio ${ }^{35}$. El imperio abarcaba la actual República y los hoy Estados norteamericanos de California, Arizona, Nuevo México, Arkansas y Texas, así como parte de los de Nevada, Oregon, Utah y alguno más.

El Congreso había acordado, previamente y por unanimidad, el 22 de junio de 1822, conceder al hijo mayor del emperador, Agustín Jerónimo, el título de príncipe imperial y a los demás hijos el de príncipe mexicano, todos con el tratamiento de Alteza; al padre, José Joaquín, el de príncipe de la Unión y a la hermana, Nicolasa, el de princesa de Iturbide. El reinado del nuevo soberano fue inestable y breve y, ya desde los meses de su anterior regencia, tuvo que soportar la presión republicana, materializada en pronunciamientos militares, particularmente el de Vicente Guerrero (1822), el de Antonio López de Santa Anna, con sus Planes de Veracruz (diciembre de 1822) y de Casa Mata (1 de febrero de 1823). Al final se vio obligado a abdicar y el 19 de marzo abandonó el país, siendo condenado por el Congreso del Estado de Tamaulipas. Estando ya en Europa (Florencia y Londres) e ignorante de esta última decisión, regresó el 14 de julio de 1824 y tras su desembarco en Soto la Marina fue detenido y fusilado cinco días después ${ }^{36}$.

35 Según GIL MUNILLA, O.: «Iturbide. El sentido de la emancipación americana», Estudios Americanos, 6 n. ${ }^{\circ}$ 23-24 (1952), pp. 165-187, p. 178, el generalísimo aceptó para defender los intereses de la burguesía en unos términos diferentes a los del primer período de la emancipación. Ver además, ROBERTson, W.S.: Iturbide of Mexico, Durham, 1952; y CAMPS, J.A.: The Liberators of Mexico: Hidalgo, Morelos, Iturbide, Nueva York, 1954.

${ }^{36}$ Cf. Torrente, M.: Historia de la revolución hispanoamericana, III, Madrid, 1830, p. 290 (en nota). 
Una de las consecuencias inmediatas del experimento monárquico iturbidense fue la repercusión que tuvo en el ánimo del general argentino José de San Martín al organizar los nuevos Estados americanos. César Pacheco, estudiando el monarquismo del Protector, publicó una carta confidencial del mismo al general José Canterac $^{37}$, tratando de obtener de él una respuesta favorable a un proyecto que preveía la creación de tres monarquías a base de los virreinatos de Nueva España, El Perú y Nueva Granada. Apoyaba su argumentación en los mencionados Plan de Iguala y Tratado de Córdoba y en un dictamen presentado el 25 de junio de 1821 en las Cortes de Madrid ${ }^{38}$. Según él, el diputado Ramírez proponía, en nombre de la diputación de Ultramar, la creación de tres secciones de Cortes en América con sus respectivas sedes en las ciudades de México, Lima y Santa Fe que, con algunas limitaciones, tendrían las mismas facultades que las de la Metrópoli. En cada una de ellas habría una delegación que ejercería, en nombre del rey, el poder ejecutivo y estaría presidida por una personalidad de libre elección del monarca, no excluido un miembro de su familia, en cuyo caso Fernando VII podría haber escogido a sus hermanos Carlos y Francisco de Paula y a su sobrino segundo Sebastián, infantes de España, aunque este último debería haber esperado hasta alcanzar la mayoría de edad.

La personalidad elegida sería responsable sólo ante el rey y las Cortes generales y gobernaría con cuatro ministros: de Hacienda, de Gracia y Justicia, de Guerra y Marina y de Gobernación. Habría, asimismo, tres secciones del Consejo de Estado y, finalmente, el comercio entre estos tres nuevos entes políticos y la Metrópoli sería considerado interior. El proyecto, como se ve, se encaminaba a favorecer los anhelos ultramarinos de independencia, pero conservando al mismo tiempo ciertos lazos de unión con Madrid. Es preciso tener en cuenta, y esto lo pone de relieve el propio San Martín, que cuando las Cortes conocieron estas propuestas aún no tenían noticia de los sucesos del Perú, de los triunfos de las tropas insurgentes en Colombia y de la proclamación de la independencia de Guatemala ${ }^{39}$.

El proyecto de San Martín enlazaba con los propósitos de Simón Bolívar de crear una monarquía cuya capital sería Lima; ambos se habían entrevistado en Guayaquil donde, entre otras cosas, trataron del régimen político, pero, al parecer, no

37 PACHECO VÉLEZ, C.: «Sobre el monarquismo de San Martín», Anuario de Estudios Americanos, 9 (1952), pp. 457-480. La carta está fechada en Lima el 11 de diciembre de 1821 y se conserva en el AGI, Indiferente general, leg. 313. Cf. ORTEGA, E.C.: José de San Martín, doctrina, ideas, carácter y genio, Buenos Aires, 1950.

38 Diario de las sesiones de Cortes. Legislatura de 1821, II, pp. 2476-2477. No es cierto, como afirma San Martín en su carta, que la proposición fuese aprobada. Tal vez, dice PACHECO, C.: «Sobre el monarquismo ...», p. 469, el error se debe a que la noticia llegó al general adulterada por la Gaceta inglesa, de la que él habla, y su entusiasmo por lo que veía como principio que facilitaría la mutua inteligencia hizo todo lo demás. Con posterioridad, las Cortes - Diario de las sesiones de Cortes. Legislatura extraordinaria, p. 1975-, en la sesión de 24 de enero de 1822, rechazaron la referida proposición.

39 HenaO, J.M.: Historia de Colombia, Bogotá, 1952; y JaRAmILlo URIBE, J.: El pensamiento colombiano en el siglo XIX, Bogotá, 1964. 
hubo acuerdo por parte del segundo y San Martín dimitió como Protector ante el Parlamento peruano el 20 de septiembre de 1822 y dos años después zarpó rumbo a Europa, donde moriría muchos años después (Boulogne, 1850). La ambición de Bolívar, según matiza Salvador de Madariaga, era singular, la de ser monarca sin ser rey - monócrata era el término acuñado—, aspirando a formar un imperio español de América y hacerse proclamar, previa estudiada resignación de poderes, por el Congreso que en 1826 reunió en Panamá, monarca de ese imperio o federación con el título de Libertador. También estaba dispuesto a secundar los deseos de Francia, expresados por el presidente del Consejo de ministros Jules Auguste, príncipe de Polignac, y abierto a las sugerencias de Gran Bretaña -así se lo expresó al agente J. Maling - de establecer monarquías regidas por príncipes europeos o por generales de la revolución americana; aunque insinuaba que como el título de rey no era popular convenía adoptar el de inca al que los indios son muy adictos ${ }^{40}$.

Fuera del ámbito español, pero en directa conexión con el proceso emancipador iberoamericano, el caso del Brasil tiene una cierta similitud con el Plan de Iguala en lo que se refiere al ejercicio personal de la soberanía por el propio rey de la Metrópoli o por su heredero. En efecto, el rey de Portugal João VI y su familia ${ }^{41}$ tuvieron que viajar en 1808 a tierras brasileñas y en marzo se instalaron en Río de Janeiro. El país, que hasta entonces era un principado unido a la Corona portuguesa, fue elevado a reino en 1815, permaneciendo allí seis años más el rey de ambas coronas. Cuando João VI regresó a Lisboa, su hijo mayor, Pedro, se quedó en el Brasil como regente o gobernador (abril de 1822), y al declararse la independencia en Ypiranga el 7 de septiembre se sumó a ella, siendo proclamado emperador el 12 de octubre, con el nombre de Pedro I, gobernando bajo una constitución.

Al morir João VI, el 10 de marzo de 1826, el sucesor legítimo del reino de Portugal era el emperador Pedro I, quien reinó allí con el nombre de Pedro IV hasta su abdicación en favor de su hija María II el 2 de mayo del mismo año; y, ante las disensiones políticas que hacían inestable el gobierno del Imperio, abdicó también la Corona brasileña en su hijo Pedro II, regresando a Portugal donde, en nombre de su hija María, que sólo tenía siete años, se hizo cargo de la regencia del reino, sacudido por las luchas entre miguelistas y liberales. Cuando sucedió a su padre, el nuevo emperador brasileño también era menor de edad, pues tenía seis años, por lo que gobernó un Consejo de Regencia hasta alcanzar la mayoría el 23 de julio de 1840. Tras un largo reinado, de tranquilidad y progreso, en el que personificó la figura de un monarca ilustrado y mantuvo el prestigio continental del Imperio, Pedro II también regresó a Europa, en 1889, dejando como regente a su hija Isabel, en

40 Madariaga, S. de: Bolívar, II, México, 1951, pp. 314, 326 y 328. Cf. Villanueva, C.A., La monarquía en América, II, París, 1913. Véase también, Belaunde, V.A.; BeníteZ, J.P.; Cuevas Cancino, F.; Donoso, R.; FernándeZ, J.F.; y PorRas Troconis, G.: Estudios sobre el «Bolívar» de Madariaga, Caracas, 1969.

41 La familia real portuguesa estaba emparentada multilateralmente con la española: la reina, Carlota Joaquina, era hija de Carlos IV; una hija del rey, Isabel, era segunda mujer de Fernando VII; una hermana, María Ana Vitória, princesa da Beira, estaba casada con el infante español Gabriel; y otras dos, María Teresa y María Francisca, habían contraído matrimonio sucesivamente con el infante español Carlos. 
quien abdicó el 15 de noviembre del mismo año, fecha en que los militares positivistas proclamaron la República ${ }^{42}$.

En las Antillas, declarada la independencia de Haití en Gonaïves el 1 de enero de1804, Jean-Jacques Dessalines, nacido esclavo, fue nombrado gobernador vitalicio, pero en septiembre se proclamó emperador con el nombre de Jacques I. Asesinado en 1806, el país se escindió en dos Estados; en el del norte Henri Christophe hijo de esclavos, generalísimo vitalicio de las Fuerzas de Mar y Tierra, fue proclamado rey el 28 de marzo de 1811 con el nombre de Henri I e intentó sentar las bases para un Estado negro, pero fue depuesto el 6 de octubre de 1820, suicidándose dos días después en su palacio de Sans Souci, cercado por insurgentes. La crueldad, la megalomanía y un desproporcionado mimetismo del fasto napoleónico caracterizaron estos dos accidentados reinados. A pesar de ello aún se verificó un tercer ensayo monárquico, pues Faustin Soulouque, presidente de la República desde el 1 de marzo de 1847, también se proclamó emperador con el nombre de Faustin I el 26 de agosto de 1849, aunque fue derrocado el 15 de enero de 1859 , teniendo que exiliarse ${ }^{43}$.

En América del Norte se logró que Canadá, tras la unión de sus territorios Alto y Bajo en 1840, se convirtiese en dominion británico en 1867, aceptando la soberanía del rey de Gran Bretaña e Irlanda, bajo la que aún se rige en el seno de la Commonwealth. En América central insular también hay que enumerar otras diez monarquías bajo la soberanía del rey británico: Antigua y Barbuda, Barbados, Belize, Granada, Jamaica, Las Bahamas, San Cristóbal y Nieves, San Vicente y Las Granadinas, Santa Lucía, y Trinidad y Tobago, todos pequeños Estados que obtuvieron la independencia del Reino Unido de Gran Bretaña e Irlanda del Norte entre 1962 y 1983 y están integrados también en la Commonwealth.

La inestabilidad política de las recién proclamadas repúblicas en Hispanoamérica propició de algún modo la aparición de proyectos o intentos de instauración monárquica en algunas de ellas. Así en las Provincias Unidas de La Plata el ideario monárquico contó con partidarios y, en concreto, el coronel Le Moyne, enviado oficioso de Francia cerca del jefe de las mismas, Juan Martín de Puyrredón, le sugirió el 2 de septiembre de 1818 el establecimiento de un reino en cuyo trono se sentaría Louis Philippe, duque de Orléans, más tarde rey de los franceses. En octubre Puyrredón confió a un enviado extraordinario el encargo de proseguir la negociación, pero el presidente del Consejo de ministros, Dessolle, descartó la candidatura fundándose en los lazos familiares que unían al duque con Louis XVIII y con Fernando VII. En realidad querría decir relaciones dinásticas, pues el parentesco era lejano y, de todas formas, nada de ello impidió que cuando Charles $\mathrm{X}$, hermano de Louis XVIII, fue destronado, el duque de Orléans fuese proclamado

42 Cf. Calmon, P.: História do Brasil, IV, São Paulo, 1947; LAcomBe, A.J.: Introdução ao estudo da história do Brasil, São Paulo, 1974; y DaLBIAN, D.: Dom Pedro, empereur du Brésil, París, 1959.

43 Cf. Bellegarde, D.: 1492-1952. Histoire du peuple haïtien, Puerto Príncipe-Lausana, 1953; y JANVIER, L.-J.: Les constitutions d'Haïti (1801-1885), París, 1886. 
rey de una nueva monarquía en 1830. No obstante, propuso al ya citado Carlos Luis, presunto heredero del ducado de Parma, sin considerar obstáculo sus mismas relaciones dinásticas y su similar parentesco con los mencionados reyes de Francia y de España ${ }^{44}$.

También un grupo de independentistas mexicanos propusieron por estas fechas a Alfonso José Marcilla de Teruel, conde de Moctezuma y de Toltengo y marqués de Tenebrón, descendiente del príncipe Pedro de Moctezuma, que se proclamase emperador de la República de México — evidente contradicción, a menos que retuviese el sentido romano de res publica, que no se tratase de un título formal o que se despojase al término emperador de toda consideración monárquica-, pero la proposición no sólo resultó inútil, sino que al candidato se le privó de todos sus títulos y se le confiscaron sus bienes, sin duda al considerársele traidor a la patria ${ }^{45}$.

En Ecuador el presidente de la República, general Juan José Flores, fue derrocado en 1845 por los liberales en Guayaquil después de quince años de mandato -régimen floreano-, y tras concedérsele una pensión fue enviado a Europa donde se reunió con los políticos españoles Martínez de la Rosa y Ángel Saavedra, duque de Rivas. Fruto de estos contactos fue su propuesta de instauración de un reino cuya corona la ofreció a uno de los hijos de la reina gobernadora María Cristina y de su segundo marido Fernando Muñoz Sánchez, duque de Riánsares, bajo la tutela del propio Flores, pues los cinco hijos varones, Agustín-María, Fernando-María, Juan-María, Antonio de Padua y José-María, eran todos menores de edad. La reina encargó al presidente del Consejo de ministros, Javier Istúriz, la realización del proyecto mientras Flores hacía preparativos en Gran Bretaña para una expedición al Ecuador, entre 1846 y 1847, pero ante la crítica suscitada en España se desistió del plan, aunque la Asamblea de Ambato, que buscaba una solución al problema planteado por la revolución ecuatoriana de 1845, lo había llegado a considerar ${ }^{46}$.

Por otra parte, Humberto Vázquez Machicado ${ }^{47}$ refiere el intento del general Casimiro Olañeta, en 1849, de instaurar una monarquía en Bolivia. Y Jaime Delgado $^{48}$ cita el proyecto del general Mariano Paredes y Arrillaga, en 1846, de ofrecer una nueva corona mexicana a miembros de la familia real española. Al pa-

44 Bourquin, M.: Histoire de la Sainte Alliance, Ginebra, 1954, pp. 396-397, quien incurre en el error de mostrar a Luigi II, duque de Lucca y ex rey de Etruria, y a Carlo II, futuro duque de Parma, como dos personas distintas cuando se trata en realidad de una sola, la de Carlos Luis (Luigi II como heredero de su padre, Luigi I, duque de Lucca, y Carlo II como heredero de su madre, la infanta María Luisa).

45 Cf. Aguilera, F. de (marqués de Cerralbo): Una crónica de los Moctezuma, Madrid, 1954.

46 Cf. EzQuerRA, R.: «Ecuador (época independiente)», Diccionario de Historia de España, I, Madrid, 1968, p. 1206. Cf. también, PAReja y Díez Cansedo, A.: Historia del Ecuador, II, Quito, 1958 (2. ${ }^{a}$ ed.).; y GIMENO, A.: Una tentativa monárquica en América. El caso ecuatoriano, Quito, 1988.

47 VázQuez Machicado, H.: «La monarquía en Bolivia», Revista de Historia de América, n. 32 (Mex., 1951), pp. 21-82. Además, cf. Díaz Machicado, P.: Historia contemporánea de Bolivia, La Paz, 1958; y Fellman Velarde, J.: Historia de Bolivia, II-III, La Paz, 1967-1970.

48 Delgado, J.: La independencia..., p. 17. 
recer, se proyectó también sentar en un trono a un descendiente de Colón, pero no he encontrado noticias de dicho episodio ${ }^{49}$. Pero si estos últimos proyectos no llegaron a cristalizar, sí pudo realizarse otro años más tarde, después de que una asamblea de notables mexicana, de mayoría conservadora, se reuniese el 8 de julio de 1863 a raíz de la ocupación de la capital por tropas francesas, y resolviese adoptar el régimen monárquico con rango de imperio y ofreciese la corona al archiduque de Austria Ferdinand, hermano del emperador Franz Joseph. El día 11 el poder ejecutivo se convirtió en una Regencia del nuevo imperio, formada por tres miembros, y el 3 de octubre tuvo lugar el primer contacto de los comisionados mexicanos en el castillo de Miramar (Istria) con el archiduque, quien meses después suscribió el tratado homónimo, de 1 de abril de 1864, aceptando el ofrecimiento, previa renuncia de sus derechos a una eventual sucesión al trono austríaco, y tomando el nombre de Maximiliano I. Si en 1821 el Tratado de Córdoba había excluido del plan monárquico a los archiduques de Austria nietos de Carlos III, ahora se hacía realidad la ascensión al Trono imperial mexicano de un tataranieto del mismo rey ${ }^{50}$.

El nuevo emperador desembarcó en Veracruz el 19 de mayo de 1864, junto con su mujer Carlota, nacida princesa de Bélgica, y llegó a la ciudad de México el 12 de junio. Poco después se redactó el Estatuto provisional del Imperio (10 de abril de 1865), que diseñaba una monarquía hereditaria, pero al carecer de hijos Maximiliano hizo recaer la presunta sucesión en dos nietos del emperador Iturbide, Agustín (1863-1915) y Salvador (1849-1895), hijos, respectivamente, de sus hijos Ángel y Salvador. El talante liberal de Maximiliano, propugnando una monarquía moderada y confirmando las Leyes de Reforma, chocó enseguida con el conservadurismo y, al faltarle el apoyo del Gobierno francés, que había patrocinado el proyecto para frenar la hegemonía norteamericana, y la inestabilidad política caracterizaron los escasos tres años del reinado al que puso fin una insurrección armada que devolvió el poder al ex presidente Benito Juárez, previa rendición del emperador el 15 de mayo de 1867, que, hecho prisionero, fue fusilado en Querétaro el 19 de junio.

\section{INICIATIVAS DE CARÁCTER INSÓLITO O AVENTURERO}

Contemporáneamente a estos últimos acontecimientos, un abogado francés, Orélie-Antoine de Tounens, idealista exacerbado o iluso, más que aventurero, pro-

49 Por esos años los descendientes oficialmente reconocidos eran los Colón de Larreátegui, en la línea de los duques de Veragua.

50 GALINDO Y GALINDO, M.: La gran década nacional o relación histórica de la guerra de reforma, intervención extranjera y gobierno del archiduque Maximiliano (1857-1867), México, 1904-1906, 3 vols.; CoRTI, E.C.:Maximilien et Charlotte au Mexique, París, 1927; BASch, S.: Maximiliano de México, Madrid, 1943; JARAMILLO URIBE, J.: La intervención francesa y el imperio de Maximiliano cien años después, 1862 1962, México, 1965; QUIRARTE, M.: Historiografía sobre el imperio de Maximiliano, México, 1970; HASLIP, J.: The Crown of Mexico. Maximilian and his emperess Carlota, Nueva York, 1971; VAldioserA, R.: Maximiliano vs. Carlota, México, 1980; RoBles, M.: Carlota. El fulgor de los cetros, México, 1999; y VILLALPANDO CÉSAR, J.M.: Maximiliano, México, 1999. 
tagonizó en tierras de Chile y Argentina unas hazañas si duda pintorescas, aunque no exentas de cierta lógica. Nacido en Chourgnac (Dordogne), el 12 de mayo de 1825, en el seno de una familia de la pequeña nobleza venida a menos $^{51}$, fue un acreditado funcionario de Périgueux y, en el ámbito de sus conocimientos jurídicos, se interesó por el derecho de gentes, lo que unido a su atracción por la obra de Alonso de Ercilla La Araucana, le llevó a escribir una tesis titulada La conquista y la propiedad ante el derecho de gentes. Su error, sin embargo, fue poner en práctica, desoyendo voces autorizadas de su entorno profesional y familiar, unas ideas que chocaban abiertamente con el derecho internacional entonces vigente.

Estas ideas consistían en conquistar y apropiarse de la Araucania, territorio bajo soberanía de Chile, situado al sur ${ }^{52}$. En efecto, se embarcó en Marsella, en junio de 1858, en unión de dos compañeros, los granjeros Desfontaines y Lachaise, rumbo a Valparaíso y en octubre de1860 se internaron en el territorio araucano, no sin antes haber discutido su proyecto con su amigo Courceil Seneuil, profesor de la Universidad de Santiago de Chile, quien no sólo lo disuadió sino que lo tuvo por loco. No así los aborígenes, que sintonizaron con sus ideas liberalizadoras, y el propio jefe de los caciques, Quilapán, aceptó el plan, coincidente con la leyenda, bastante generalizada en América, de que un hombre blanco llegaría en nombre del rey; naturalmente Tounens tuvo que explicarles que ese rey no era el de España, sino un amigo suyo, Napoleón III, emperador de los franceses. Todo acorde, el 17 de noviembre de 1860 fue proclamado rey con el nombre de Aurelio-Antonio I.

Comenzó su reinado con la promulgación de una proclama fundamental, cuyo primer artículo decía: Se establece en Araucania una monarquía constitucional y hereditaria ${ }^{53}$. Y tres días después, el 20 de noviembre, hacía público un segundo documento por el que la Patagonia queda reunida desde hoy a la Araucania, formando parte integrante ${ }^{54}$; la capital del inmenso territorio resultante, algo más de un millón de $\mathrm{km}^{2}$, la estableció en el poblado de Angol, también capital de la antigua provincia de Malleco. Su plan era ofrecer a los habitantes, mapuches, los de-

51 Orélie-Antoine llegó a obtener de la Corte Imperial de Justicia el reconocimiento de la partícula de en su apellido, como descendiente de los señores de Touneins, y el derecho a llamarse príncipe, tras la negativa de los tribunales de Périgueux. Cf. LuIz M. T. y SchILLAT, M.: La frontera austral. Tierra del Fuego, 1520-1920, Cádiz, 1997, pp. 125-129.

52 El territorio está comprendido entre el río Bio-Bío (al norte) y el Calle-Calle (al sur) y entre los Andes (al este) y el océano Pacífico (al oeste) e integrado por las provincias de Arauco, Cautín, Malleco y Bio-Bío, que hoy forman parte de las regiones de Bio-Bío y la Araucania.

${ }^{53}$ La proclama tenía tres artículos más que, respectivamente, regulaban la sucesión (dentro de la familia Tounens), daban fuerza de ley a las propias ordenanzas del rey, mientras no se redactase una Constitución, y otorgaban las funciones legislativas al ministro-secretario.

54 La parte este de Patagonia, de soberanía argentina, comprende hoy las provincias de Neuquén, Río Negro, Chubut, Santa Cruz y Tierra de Fuego; la parte oeste, de soberanía chilena, está integrada actualmente por las regiones de Los Lagos, Aysén y Magallanes, salvo algún trozo. Un mapa coetáneo del reino creado por Tounens puede verse reproducido en Gran Enciclopedia Larousse, Barcelona, 1980, p. 617. 
rechos como pueblo, sin tener reparos en equiparar la doctrina clásica del derecho de gentes tal como se entendía en el siglo XVI, al derecho internacional vigente. Por ello, se limitó a participar a los presidentes de las repúblicas Argentina y de Chile su advenimiento al trono que acabamos de erigir, al tiempo que lo comunicó a los principales periódicos argentinos y chilenos. También escribió a su padre y a su hermano mayor, notificándoles una ordenaza de 1861 por la que se convertían en príncipes de Araucania y de Patagonia, con el tratamiento de Alteza Real, y poco después, el 25 de enero de 1862, estableció el orden de sucesión, con preferencia del varón en la misma línea: su padre, Jean, su hermano mayor, Jean, el hijo de éste, Adrien, y sus descendientes; y redactó una Constitución de 66 artículos, distribuidos en 9 títulos.

En este último año, 1862, se puso al frente de miles de indígenas, especialmente belicosos desde la conquista hispana, sublevados contra el Gobierno chileno, pero cayó prisionero y, procesado, el juez sobreseyó la causa y ordenó su internamiento en un manicomio de Los Ángeles, de donde podría salir si era reclamado por algún familiar o por el encargado de negocios francés. Éste, finalmente, recibió las órdenes pertinentes de su Gobierno y Tounens fue repatriado. Durante su estancia en París se dedicó a escribir libros, opúsculos y artículos, fundó dos periódicos, buscó capitales para financiar su antigua empresa y llegó a entrevistarse con Napoleón $1 \mathrm{II}^{55}$. En 1869 regresó a Araucania y reanudó la lucha, pero fue expulsado, retornó otra vez y fue expulsado de nuevo.

En 1872 se persuadió, al fin, de la inutilidad de sus esfuerzos, aunque mantuvo la idea, creando una Corte en el exilio, con sede en la calle Lafayette (hoy superficie comercial del mismo nombre), fundando la Orden Real y Noble de la Estrella del Sur, que se sumaba a la Real Orden de la Corona de Acero, creada en 1869, ambas dinásticas. En la de la Estrella del Sur, la más importante y que facilitaba el acceso a la nobleza, llegaron a ingresa, al parecer, los ex presidentes de la República Argentina, Juan Domingo Perón (1962) y de los Estados Unidos de América, Dwigth David Eisenhower (1966). Los familiares de Aurelio-Antonio habían renunciado formalmente ante notario, en 1872, a los títulos recibidos y a una eventual sucesión al trono araucano y como él no tenía descendencia, al año siguiente nombró heredero a su amigo Achille Laviarde, con los títulos de príncipe de los Aucas y duque de Kialeou, quien a la muerte de Aurelio-Antonio, en Tourtoirac, el 17 de septiembre de $1878^{56}$, le sucedió con el nombre de Achille I. El nuevo dinasta designó cónsules en Londres, Roma y Saint-Malo, que llegaron a recibir el exsequatur, sucediéndole Hypolite Cros con el nombre de Antoine II. Al menos en 1994 figuraba como príncipe de Araucania

55 Tounens ya le había escrito pocos años antes, durante su estancia en Valparaíso, donde el periódico El Mercurio relató sarcásticamente su conquista, y había llegado a ofrecer a colonos lo que llamó La Nueva Francia a cambio de títulos de la Deuda que emitió, pero nadie suscribió.

56 En su tumba, erigida en 1937, se lee: Ici repose Tounens, Antoine Orélie ler roi d'Araucanie et de Patagonie. 
y de Patagonia Philippe I (de Boiry), quien había fundado la Académie d'Études Araucaniennes ${ }^{57}$.

Avanzado ya el siglo XIX, surgieron otros dos casos de iniciativas monárquicas en el marco de lo insólito o de la aventura. La primera, con tintes de reclamo literario, fue la del reino de la isla antillana de Redonda, descubierta por Cristóbal Colón en su segundo viaje, de 1 '5 $\mathrm{km}^{2}$. Y prácticamente desierta, hoy bajo soberanía de Antigua y Barbuda. Fue supuestamente comprada en 1865 por un predicador metodista, naviero de la vecina isla de Montserrat, pero el Gobierno británico, adelantándose al norteamericano, la anexionó en 1872 a su país al comprobar la existencia de fosfato de alúmina en su subsuelo. El hijo del predicador, el novelista Matthew Philip Shiel (o Shiell) fue proclamado por su padre, para celebrar su nacimiento (1865) y coronado en 1880 rey de Redonda con el nombre de Philip I, sin haber visitado la isla y con sólo quince años de edad. Cuando Shiel murió en 1947 dejó como sucesor a un escritor casi desconocido John Gawsworth ${ }^{58}$, quien sin tomar tampoco posesión del presunto trono firmó algún escrito, tal vez en son de broma, como John I, king of Redonda, y llegó a conceder títulos ducales a otros literatos, como el de Thuana a Henry Miller y el de Cervantes Pequeña a Lawrence Durrell. Al morir, el 6 de julio de 1970 en el Brompton Hospital (Chelsea, Londres), pobre y olvidado, heredó el ficticio reino John Wynne-Tyson, nacido en 1924, con el nombre de John II, pero en 1997 abdicó en el novelista Javier Marías, quien asumió el nombre de Xavier I y fundó la editorial Reino de Redonda, que ha creado en 2001 el premio homónimo, al que se adscribe un título ducal figurativo ${ }^{59}$. Pese a su carácter literario-fantástico, el reino redondino es objeto de reivindicaciones y Xavier I es cuestionado por el rey Leo (William Leonard Gates) y el rey Roberto el Calvo (Robert Williamson).

El segundo caso de iniciativa monárquica se produjo en territorio de los Estados Unidos de América y partió de una denominada Orden Aria de San Jorge, con sede central en Boston y delegaciones en cinco Estados de la Unión. Al menos hasta 1904 había organizado reuniones y conferencias, publicado artículos de

57 Merecería la pena realizar un estudio histórico serio de esta experiencia araucana que, posiblemente, trasciende la mera aventura, por sus conexiones doctrinales con la primera conquista hispánica o, al menos, por su probable interés antropológico y socio-político. El propio Tounens publicó dos obras, Orélie Antoine I, roi d'Araucanie et de Patagonie, París, 1863 y Retour en France du roi d'Araucanie et de Patagonie, París, 1870, que, tal vez han servido de fuente a J[uan] B[ALANSó] AmER para su artículo de divulgación «El estrambótico rey de la Patagonia», Historia y Vida, n. ${ }^{\circ} 32$ (1970), pp. 22-31. Véase también VÁZQUEZ AcuÑA, I.: «Breve noticia de la monarquía arauco-patagónica», Hidalguía, n. 21 (1957), pp. 265ss.; y PHILIPPE, prince d'Araucanie: Histoire du royaume d'Araucanie, París, 1979. Por otra parte, las hazañas de Tounens fueron llevadas al cine en Argentina por Carlos Sorín, quien en 1986 dirigió el filme La película del rey.

58 John Gawsworth era el seudónimo utilizado por Terence lan Fytton Armstrong y no debe confundirse con el conocido John Galsworthy. Cf. MARíAS, J.: «El hombre que pudo ser rey», EPS (23 mayo 1983), pp. 11-12, y su novela Negra espalda del tiempo, Madrid, 1998, pp. 22-25, 153-169 365-369. Sus noticias las amplía en otra, Todas las almas, Barcelona, 1989.

59 Entre los más de veinte títulos dúchales redondinos se encuentran los de Simancas (John Elliott), Trémula (Pedro Almodóvar), Corso (Arturo Pérez-Reverte), Caronte (Fernando Savater) y Malmundo (Luis Antonio de Villena). El lema de la isla, ride si sapis, proporciona claves. 
prensa y lanzado una proclama en favor del príncipe real de Baviera, Rupprecht (hijo del rey Ludwig III, destronado en 1918), a quien había ofrecido, tal vez en compensación, una hipotética corona que, obviamente, rehusó60. Cabe añadir un tercer caso, reflejado en la literatura, aunque el uso de los términos imperio y emperador es sólo ficción: el de Luis Gálvez y Rodríguez de Arias, nacido en San Fernando (Cádiz) en 1864 y fallecido en Madrid en 1935, quien el 14 de julio de 1899 declaró la independencia del territorio de Acre, situado en la cuenca amazónica, entre Bolivia, Brasil y Perú, y disputado por su riqueza en caucho. Optó por el régimen republicano, acorde con sus ideas, implantando una legislación avanzada, promulgando planes de urbanismo, entre otras medidas. Apenas transcurridos ocho meses fue depuesto y el Gobierno boliviano, por decreto de 8 de marzo de 1900, incorporó el territorio a su país, aunque por un plebiscito de 15 de septiembre de 1909 se reintegró a la soberanía del Brasil y desde 1962 es uno de sus veintiséis Estados ${ }^{61}$.

\section{CONCLUSIONES}

En definitiva, el tema de las instauraciones monárquicas en América no es algo aislado, excepcional o novedoso; la novedad del hecho histórico reside más bien en las sucesivas proclamaciones de las repúblicas al iniciarse el siglo XIX. Desde su descubrimiento y conquista, en América se fueron creando monarquías cuya soberanía fue ejercida por reyes europeos, de España, Portugal, Francia, Gran Bretaña, etc. Incluso en la época precolombina se destacaron dos grandes imperios, el azteca, base de Nueva España, y el inca, base del Perú, los dos primeros virreinatos, creados en el siglo XVI. Cosa distinta es el proceso de estructuración interna (colonias, provincias, reinos), el grado de organización de sus instituciones y la variedad de las mismas. Estos reyes o algún miembro de su familia, salvo el caso mencionado de João VI, rey de Portugal, no residieron en ellas ni las visitaron. Cabe subrayar, sin embargo, la singularidad de la Monarquía española, cuyo soberano añadió a su título de rey de las Españas (Castilla, León, Aragón, Navarra, Granada, etc.) el de rey de las Indias (Nueva España, Perú, Nueva Granada y Río de la Plata, cuyos virreyes tuvieron su sede, respectivamente, en México, Lima, Santa Fe de Bogotá y Buenos Aires).

Por otra parte, los proyectos de recreación monárquica de fines del siglo XVIII estaban en conexión con los procesos de emancipación, a punto de iniciarse.

60 José Luis BARCELó, respondiendo a una consulta (Historia y Vida, n. ${ }^{\circ}$ 25, pp. 5-6) asegura que el príncipe Rupprecht era descendiente del príncipe Charles Edward, a quien unos congresistas también ofrecieron una corona, como expuse al principio. Si es cierta la descendencia debe serlo por línea no legítima, tal vez a partir de una hija natural, Charlotte, pues Charles Edward no tuvo sucesión de su mujer Louisette, nacida princesa de Stolberg-Gedern.

61 La ficción se desarrolla en las novelas Gálvez, emperador del Amazonas, de Marcio Souza (1981), de carácter abiertamente paródico, y La estrella solitaria, de Alfonso Domingo (2003). 
Éstos eran ya inevitables, pero podían paliarse tratando de salvar el régimen monárquico y los mayores y mejores vínculos de los nuevos reinos ultramarinos con la Metrópoli. Estos proyectos o intentos, aunque similares, fueron diversos. Así, los del conde de Aranda o de José de Ábalos al proponer sentar en los diseñados tronos a familiares del rey, que de haber sido llevados a la práctica, tal vez no hubiesen impedido la independencia, pero sí la hubiesen diferido como ocurrió con la Monarquía brasileña, o por mejor decir luso-brasileña, que llegó a durar medio siglo. Los de Godoy, San Martín, coincidente con los propósitos de Bolívar, o Iturbide no excluían tales estrategias, pero ocultaban ambiciones personales o deseos de independencia.

Ya entrado el siglo XIX hubo experiencias que manifestaron abiertamente tales ambiciones personales, como los de Haití, teñidos, además, de cruel megalomanía. Otras iniciativas resultaron inviables, como la de Dessolles, en las Provincias Unidas de la Plata, y la de Olañeta, en Bolivia; o ilusorias, como la de Mina, en Nueva España; o ficticias, como la de Shiel, en la isla de Redonda; o infructuosas, como la de la Orden Aria de San Jorge, en los Estados Unidos de América. Tampoco tuvo éxito la instauración del imperio de Maximiliano, porque el proyecto obedecía a intereses europeos de la mano de Francia, aunque duró tres años. En fin, la iniciativa personal de Tounens, en los territorios de Araucania y Patagonia, basada en la doctrina clásica del derecho de gentes, también resultó inviable.

Es posible que haya habido más proyectos o iniciativas que o bien yacen ocultos en archivos por falta de trascendencia o porque fueron protegidos por el secreto. Incluso en las últimas décadas del siglo $\mathrm{XX}$ ha proliferado un sinnúmero de micro monarquías sedicentes o fantasmas, varias de ellas creadas por aventureros, con fines espúreos, en los Estados Unidos de América, Canadá, El Brasil o Argentina; el reino de Talossa, en Milwaukee (Wisconsin), o el principado de Thera, en Catamarca (Argentina), pueden citarse entre las más extravagantes. En todo caso, poco tienen que ver con el objeto de este artículo.

\begin{tabular}{|c|c|c|c|c|c|}
\hline Año & Promotor & Ambito territorial & Duración & Monarca & Título \\
\hline 1762 & W. Pitt & Trece colonias & Proy. & Pr. británico & $?$ \\
\hline 1768 & $\begin{array}{c}\text { Campomanes / } \\
\text { Floridablanca }\end{array}$ & América esp. (1) & Proy. & $\ldots$. & $\ldots$. \\
\hline h. 1776 & Varios congresistas & Trece colonias & Proy. & Pr. Charles Edward & $\ldots$. \\
\hline 1781 & J. de Ábalos & América sept. & Proy. & Inf.. de España & Rey \\
\hline 1783 & Aranda & América esp. & Proy. & Inf. de España & Rey (2) \\
\hline 1787 & Aranda & La Plata & Proy. & Inf. de España & $\ldots$ \\
\hline 1804 & J.-J. Dessalines & Haití & 1804-1806 & Jacques I & Emperador \\
\hline
\end{tabular}

(1) Salvo Cuba, Puerto Rico y una parte septentrional sin determinar.

(2) El rey de España llevarìa el título de emperador. 


\begin{tabular}{|c|c|c|c|c|c|}
\hline Año & Promotor & Ambito territorial & Duración & Monarca & Título \\
\hline h. 1806 & Godoy & América esp. & Proy. & $\begin{array}{l}\text { Inf. de España } \\
\text { o Godoy }\end{array}$ & Pr. regente \\
\hline 1811 & H. Christophe & Haití (Norte) & $1811-1820$ & Henri I & Rey \\
\hline 1816 & J. Mina & Nueva Esp. & Proy.. & J. Bonaparte & $\ldots$. \\
\hline 1818 & Gob. francés (3) & PP.UU. de la Plata & Proy. & D. de Orléans (4) & Rey \\
\hline 1819 & Dessolle & PP.UU. de la Plata & Proy. & Inf. Carlos Luis & $\cdots$ \\
\hline h. 1820 & $\begin{array}{l}\text { Independentistas } \\
\text { mexicanos }\end{array}$ & Nueva Esp. & Proy. & C. de Moctezuma & Emperador \\
\hline 1821 & (Iguala/Córdoba) & Nueva Esp. & $1822-1823$ & Agustín I & Emperador \\
\hline 1821 & J. de San Martín & $\begin{array}{l}\text { Nueva Esp., Perú, } \\
\text { Nueva Granada }\end{array}$ & Proy. & $\cdots$ & \\
\hline 1822 & (Ypiranga) & El Brasil & $1822-1889$ & Pedro I y Pedro II & Emperador \\
\hline 1826 & S. Bolívar & América esp. & Proy. & S. Bolívar & $\begin{array}{c}\text { Libertador } \\
\text { o Inca }\end{array}$ \\
\hline 1829 & Gob. español & Gran Colombia & Proy. & Pr. europeo (5) & Rey \\
\hline 1846 & J.J. Flores & El Ecuador & Proy. & Muñoz y de Borbón & $\ldots$ \\
\hline 1846/47 & M. Paredes Arrillaga & México & Proy.. & Inf. de España & $\cdots$ \\
\hline 1849 & C. Olañeta & Bolivia & Proy. & $\ldots$ & $\ldots$ \\
\hline 1849 & F.E. Soulouque & Haití & 1849-1859 & Faustin I & Emperador \\
\hline 1860 & O.-.A. Tounens & Araucania/ Patagonia & $1860-1862$ & Aurelio- Antonio I & Rey \\
\hline $\begin{array}{c}1867 \\
1864\end{array}$ & $\begin{array}{l}\text { Gob. británico } \\
\text { Representantes } \\
\text { políticos }\end{array}$ & $\begin{array}{l}\text { Canadá } \\
\text { México }\end{array}$ & $\begin{array}{c}\text { Vigente } \\
1864-1867\end{array}$ & $\begin{array}{c}\text { Victoria y sucesores } \\
\text { Maximiliano I }\end{array}$ & $\begin{array}{c}\text { Rey } \\
\text { Emperador }\end{array}$ \\
\hline 1880 & Shiel (senior) & Redonda & Vigente & Philip I & Rey \\
\hline 1899 & L. Gálvez & Acre & 1899-1900 & L. Gálvez & Emperador \\
\hline h. 1900 & O. Aria de S. Jorge & EE.UU. de Am. & Proy. & Pr. real de Baviera & $\cdots$ \\
\hline $\begin{array}{l}1962- \\
1983\end{array}$ & Gob. Británico & Diez EE. del Caribe & Vigente & Isabel II & Rey \\
\hline
\end{tabular}

(3) Su enviado oficioso fue el coronel Le Moyne.

(4) Como sucesor de Bolívar, a quien se le nombraba jefe vitalicio de Estado.

(5) Louis Philippe, futuro rey de los franceses, pero, descartado por su parentesco con Louis XVIII y Fernando VII, fue propuesto Luigi, heredero del ducado de Parma. 